\title{
THE EFFECTS OF BLOOD RUMEN CONTENT MIXTURE (BRCM) MEAL SUPPLEMENTED WITH YEAST ON THE PERFORMANCE AND GUT MICROBIAL POPULATIONS OF BROILER CHICKENS
}

\author{
OYEDEJI, J.O., AJAYI, H.I., EPOUDO, I., EDEM, I.I. and SOKONDI, R.S \\ Department of Animal Science and Animal Technology, Benson Idahosa University, PMB 1100, \\ Benin city, Edo state, Nigeria \\ Corresponding Author Email: joyedeji@biu.edu.ng
}

\begin{abstract}
One hundred and twenty (120) arbor acre strain day old broiler chicks were used to investigate the effects of blood rumen content mixture (BRCM) meal supplemented with Levucel SB yeast on the performance and gut microbial populations of broiler chickens. Four diets were formulated both at the starter and finisher stages of the experiment. Diet 1 had neither blood rumen content mixture (BRCM) nor yeast supplementation. However diets 2, 3 and 4 contained 3.5, 7.0 and 10.5\% BRCM respectively all supplemented with $2.5 \mathrm{~g} / \mathrm{kg}$ diet Levucel SB yeast. Dietary treatments were replicated three times using a completely randomized design. Each replicate treatment had 10 chicks. The experiment lasted for eight weeks. Results showed a significant increase $(p<0.05)$ in feed intake. The highest feed intake (2.80 kg per bird) was recorded among broiler chickens fed on diets containing 3.5 and $10.5 \%$ BRCM $(p<0.05)$. Body weight gain and feed conversion ratio were similar for birds in all dietary treatments $(p>0.05)$. Ileal and caecal microbial populations were significantly increased both at 10-2 and 10-3 serial dilutions $(P<0.05)$. All dietary treatments had Bacillus species of bacteria in their isolates. Only dietary treatments containing BRCM supplemented with Levucel SB yeast had Streptococcus and Staphylococcus species of bacteria in the isolates from the ileum and ceacum portions of the small intestine. It was concluded that when supplemented with yeast, BRCM meal up to $10.5 \%$ in broiler feed had no detrimental effect on broiler performance. It also enhanced the development of beneficial gut microbes.
\end{abstract}

Key Words: Broilers, Blood Rumen Content, Performance, gut microbes, Levucel SB yeast

\section{INTRODUCTION}

The importance of feed in livestock production cannot be overemphasized. Feed accounts for between 60 and $80 \%$ of the total cost of producing poultry (Adebowale, 1998). Balogunet al. (2001) attributed the unsteady expansion of poultry industry to fluctuation in the supply of good quality feed. Poultries are characterized by the best biological efficiency of nutrient transformation into quality animal protein (Oludoyi and Toye, 2012). Conventional feed ingredients such as maize, fish meal, soybean, groundnut cake, wheat and others are competitively used by man, livestock and 
industries, hence are very costly. Prices of most conventional feedstuffs respond to economic and seasonal factors (Bolu and Ibikunle, 2009). Efforts at reducing cost of feeding poultry have focused on the use of alternative, underutilized and cheaper feed resources.

One of such less utilized feed resources is the rumen content and blood of bovine animals. The rumen content is the content of the first stomach compartment of the ruminants. The rumen and its contents account for about $80 \%$ of the capacity of the adult ruminant stomach and it is rich in nutrients including food particles, microorganisms and fermentation products (Church, 1973). The reported proximate composition of blood rumen content mixture varied depending on the ratio between blood and the rumen content (Adeniji, 1996,Balogunet al., 2001). On average, reports shows that blood rumen content mixture contains $21.8 \%$ Crude protein, $30.3 \%$ crude fibre, $6.1 \%$ Ether extract and $11.5 \%$ total ash (Adeniji, 1996). A number of reports show that rumen contents were investigated as possible feed ingredient for farm animals (Adeniji, 1996, Balogunet al., 2001). Adeniji (1996) fed bovine blood rumen content meal to laying hens with no detrimental effect on the bird's performance.

The major content of the rumen is of plant origin. Most feed ingredients of plant origin contain considerable amount of fibre (Non starch polysaccharide plus lignin) with the majority being insoluble (Patterson and Burkholder, 2003). Rumen content being predominantly made up of fibrous materials falls under this classification. Poultry as a monogastric animal has little or no ability to effectively make use of such high fibre containing feed ingredient unless an exogenous substance is used to help the birds break down the fibrous material. Charlie (1998) reported that supplementation of $2-3 \mathrm{~g}$ yeast per $\mathrm{Kg}$ diet is effective in improving growth and feed efficiency in broilers fed high fibre diets. Oyedeji et al. (2008) reported a significant fibre digestibility when Levucel SB yeast was supplemented at $300 \mathrm{mg} / \mathrm{Kg}$ in broiler diets containing high fibre. Yeast in poultry diet stimulates the growth of some anaerobic bacteria including cellulolytic and lactic acid utilizing bacteria (Chaucheyraset al.,1995, Yoon and Stern, 1996). The mode of action of probiotics such as yeast in poultry has been explained to be that of maintaining normal intestinal microflora by competitive exclusion and antagonism, altering metabolism by increasing digestive enzyme activity, improving feed intake and digestion and stimulating immune system (Apata, 2008, Kizerwitter and Binek, 2009). 
Adejumoet al., (2005) reported that indirect benefit of yeasts can arise when yeast and metabolic enzyme break down the fibrous and nutrient components of the ration. The microorganisms that colonize the gastrointestinal tract during the early post hatch period forms a synergistic relationship with their poultry host and may have a highly significant impact on uptake and utilization of energy and other nutrients (Chichlowskiet al., 2007).

Rumen content by nature contains microorganisms mainly bacteria and other microorganisms (Church, 1973). It is possible that feeding blood rumen content meal can influence the growth of beneficial microorganisms in broiler bird's gut.

In Benin City, Edo state of Nigeria, the waste generated from slaughter houses where hundreds of cattle are slaughtered weekly often constitute environmental problems. Informal survey by these authors reveled that tons of wet rumen contents as well as blood are thrown away as wastes on daily basis. Harnessing and processing these materials as poultry feed ingredients may assist in reducing cost of feeding.

This study was designed to investigate the effects of graded levels of blood rumen content meal supplemented with yeast, on performance and gut microbial development of broiler chickens.

\section{MATERIALS AND METHODS}

The study was conducted at the poultry unit of the Teaching and Research Farms of Benson Idahosa University, Benin city. One hundred and twenty (120) day old Arbor acre strain of broiler chicks were used in an experiment designed to determine the effects of graded level of Blood Rumen Content Mixture (BRCM) on the growth performance and gut microbial population of Arbor acre broiler chickens.

The blood and rumen content were collected at the abattoir unit of Benson Idahosa University Teaching and Research farms at the time of slaughtering cattle. The blood was collected directly from the neck of the slaughtered animal into a clean basin. After removing the visceral, the rumen was carefully split open and the content evacuated into a clean container. The bovine blood rumen content mixture was immediately prepared using a ratio of one part of blood to four parts of rumen content. The two components were properly mixed together, and then boiled at $800 \mathrm{C}$ for three hours. The boiled mixture was then properly sundried to constant weight. The dried mixture was milled before incorporation into broiler diets. 


\section{Diet Formulation and Animal Experimentation}

Four broiler starter diets and four broiler finisher diets were formulated and used for this study (Tables 1and 2). In both starter and finisher phases, diet 1 which had neither blood rumen content mixture nor Levucel SB yeast served as control, while diets 2, 3 and 4 had 3.50, 7.0 and $10.5 \%$ Blood Rumen Content Mixture (BRCM), respectively. Diets 2, 3 and 4 were supplemented with $2.5 \mathrm{~g}$ yeast $/ \mathrm{kg}$ diet. Broiler chicks were randomly distributed into the four dietary groups. There were thirty (30) chicks in each group replicated thrice on the basis of ten (10) chicks per replicate. The same dietary groups were maintained for both starter (0-4 weeks) and finisher (5-8 weeks) phases. Feeds and clean drinking water were supplied ad libitum throughout the period of the experiment. Initial and weekly body weights of birds were taken. Live body weight gained by broilers was determined by subtracting the initial weight of birds from the final body weight of birds. Weekly feed intake was also recorded and the total feed intake was calculated by adding the weekly feed intake. Feed conversion ratio was calculated by dividing the total feed intake by body weight gained by bird.

\section{Microbiological Assay}

Microbiological assay was carried out at two stages. First, during the starter phase and secondly, during the finisher phase.

For each stage, six birds were randomly selected from each dietary treatment group making a total of twenty four (24) birds. The birds were slaughtered and cut open immediately for evisceration. The ileum and caecum of each bird were sectioned and their contents immediately flushed out into separate sterilized test tubes. Each stock was made up to $20 \mathrm{mls}$ by adding distilled water. Standard sterilization of all the glasswares and materials used in culturing and identification was done at $130^{\circ} \mathrm{C}$ for 1 hour. Media and distilled water used were sterilized in the autoclave at $121^{\circ} \mathrm{C}$ for 15 minutes. Work bench was disinfected before and after use with $70 \%$ ethanol. The working area was sterilized by the flame from bursen lamp. All other apparatus used were properly cleaned with cotton wool soaked in $70 \%$ ethanol.

$2 \mathrm{mls}$ of each of the sample stocks prepared for either ileal or ceacal contents of each bird was serially diluted at $10^{-2}$ and $10^{-3}$. About $44.8 \mathrm{~g}$ of nutrient agar used as culturing medium was mixed in 1.6 liters of deionized water. Pour plate method was used for inoculation. The bacteria were grown at $37^{\circ} \mathrm{C}$ for 24 hours in an incubator. Total viable count, identification and classification were carried 
out before streaking. The different microorganisms identified were sub cultured on new plates. Gram staining of the new plates was done after 24 hours.

ProximateAnalysis

Proximate compositions of the blood rumen mixture and feed samples were determined using the methods of the AOAC (1990). Moisture content was determined by drying the samples at $70^{\circ} \mathrm{C}$ for 24 hours until constant weight was achieved. Crude protein was determined using Kjedhal method, while ether extract was carried out for crude fat determination using Soxhlet apparatus. Crude fibre was determined by boiling the defatted sample serially in dilute tetraoxosulphate 6 acid followed by boiling in $40 \%$ Sodium hydroxide. The residue left after burning off the remaining carbon in a furnace was recorded as the ash content.

Statistical Analysis

Data collected were statistically analyzed using SAS (2005) package as applied to a completely randomized design. Significant means were separated using Duncan Multiple Range Test Duncan (1955).

\section{RESULTS}

Table 3 shows the proximate nutrient content of the blood rumen content mixed at the ratio of one (1) part of blood and four (4) parts of rumen content on as fed basis. Dry matter, crude protein, ether extract, crude fibre, ash and Nitrogen free extract (NFE) values are 90.47, 23.78, 9.17, 20.40, 10.87 and $26.53 \%$, respectively.

The effects of Blood Rumen Content Mixture (BRCM) meal supplemented with yeast on the performance of broiler chickens ( $0-8$ weeks) is as shown in Table 4 . Feed intake was significantly increased $(P<0.05)$. The highest feed intake $(2.80 \mathrm{~kg} / \mathrm{bird})$ occurred at 3.5 and $10 \%$ BRCM dietary inclusions. However, live body weight gain and feed gain ratio were similar for all dietary treatments $(P>0.05)$. The highest percentage mortalities were recorded at $0(7.4 \%)$ and $7(7.9 \%)$ percentage inclusions of BRCM.

The effects of dietary BRCM meal supplemented with yeast on the microbial population in ileum and caecum of broiler chicks at 4 week is shown in Table 5 . At both $10^{-2}$ and $10^{-3}$ serial dilutions, dietary BRCM significantly increased microbial populations in both ileal and caecal portions of the intestine $(P<0.05)$. 
Table 6 shows the effects of dietary BRCM supplemented with yeast on the microbial population in ileum and caecum of broiler chickens at 8 weeks. At $10^{-2}$ serial dilution a significant increase on microbial populations in both ileum (75) and caecum (119) were observed especially at $10.5 \%$ dietary inclusion of BRCM $(\mathrm{P}<0.05)$. However, at $10^{-3}$ dilution microbial populations in both ileum and caecum were significantly reduced by dietary inclusion of BRCM in broiler chickens feed $(P<$ 0.05).

The effects of Blood Rumen Content Mixture (BRCM) meal supplemented with yeast on the type of bacteria species found in lleum and caecum and broiler chickens is as shown in Table 7. All dietary treatments had Bacillus species in both ileal and caecal portions of the intestine. However, Staphylococcus species were only generally found in diets that contained BRCM, none was isolated from the diets that had no blood rumen content (control). Streptococcus species were only isolated in the ileum of chickens fed $10 \%$ dietary BRCM.

\section{DISCUSSION}

The proximate values of the Blood Rumen Content Mixture (BRCM) meal used in this study place it in the class of intermediate protein concentrate (23.75\% CP) but with high fibre $(20.40 \%)$. Other ingredients with similar characteristics include rice bran, wheat bran as well as brewery by products like brewers' dried grain. However the crude protein value of BRCM meal used in this study is lower than $31.42 \%$ reported by Adeniji and Balogun (2001) while the crude fibre value is largely similar with $18.71 \%$ reported by Adeniji and Balogun (2001). The differences could be as a result of mixing ratios of blood to rumen that differed as well as methods of processing. Furthermore, the feed materials that the animals ingested prior to the time of slaughter may differ in terms of maturity as well. The stage of ruminal breakdown of the feed materials may contribute to the nutritional quality of BRCM meal.

Generally it was observed that the average day old live weight per broiler chick used for the study was below the expected weight. Presumably, this may be attributed to breeding and hatchery problem. Fayeye and Olapade (2013) reported that incidence of small chicks was attributable to farm source of hatchable eggs as well as on the type and magnitudes of reproductive failures that occurred during incubation. The small size of chicks which they maintained throughout the experimental period could have accounted for the generally low feed intake observed in the control 
and BRCM based diets. Since birds eat according to their body size. However, despite this observation the effects of dietary treatments on the performance of the birds were still clearly defined. Contrary to the reports of Balogun et al. (2001) that feed intake was reduced by inclusion of BRCM in layers diet, a gradual increase in feed intake by broiler chickens was observed in this study. With the knowledge of poultry's limited ability to breakdown fibre in diets, Levucel SB yeast was supplemented into the BRCM containing diets as a means of aiding in fibre digestion as well as improving feed intake. Levucel SB yeast has been reported to help broiler chicks utilize high fibre diets (Oyedeji et al., 2008).

Adejumoet al.,(2005) reported that indirect benefit of yeasts can arise when yeast and metabolic enzyme breakdown the fibrous and nutrient content of the diet. The result of feed intake, weight gained and feed gain ratio reported in this study seems to confirm the growth promoting property of yeast in poultry. Ignacio (1995) reported that yeast has been traditionally used as a growth promoter in poultry and other diets. Earlier workers attributed part of the growth promoting properties of yeast to its ability to stimulate feed intake by improving palatability (Newbold et al., 1995). Generally, the mortality observed could not be attributed to dietary inclusion of BRCM meal, indicating that it is a safe ingredient for use in broiler diets.

The microbial population in the ileal and caecal portions of broiler chickens intestine as observed in this study generally increased as the graded level of BRCM increased. The significance of this is that, BRCM meal supplemented with yeast presumably provided suitable substrate for the development of these micro-organisms. Feeding, as well as altering gut micro flora development within the first two weeks post hatch has been shown to modify gut development in chickens (Patterson and Burkholder, 2003). Earlier workers have reported various genera and species of micro-organism that colonise the birds' intestines at various ages. For example, Mead (1989) reported that the major species present in the small intestines of young chicks was lactobacillus with bifidiobacteria populations becoming more dominant in the caeca at older age. Bouzaine et al. (2005) also reported that after the first week, lactobacillus predominates in the small intestine. A further report by Bouzaineet al. (2005) reveals that at 2 to 4 days post hatch, Streptococci and Enterobacteria colonize the small intestine and caecum. The isolation of Bacillus and Streptococcus and species of bacteria from the ileum and caecum of broiler chicken fed BRCM meal in this study corroborates the earlier reports (Cummings and Macfarlane, 1997 and Bouzaine, et al., 2005). 
The role of gut microbes has been speculated to be that of aiding intake and use of dietary nutrients. Chichlowskiet al. (2007) reported that microorganism that colonise the gastrointestinal tract during the early post hatch period form a synergetic relationship with their poultry host and they have a highly significant impact on uptake and utilization of energy and other nutrients. There seems therefore, on the average a direct relationship between the performance of broiler chickens fed on graded level of BRCM supplemented with yeast and the microbial population isolated from their intestines in greater number than in the intestines of broilers not fed on BRCM meal.

In summary, the results obtained in this study shows that supplementation of Levucel SB yeast in Blood Rumen Content Mixture (BRCM) diet increased microbial population in broiler chickens gut as well as enhanced nutrient utilization of the high fibre diet. Above all, dietary BRCM meal up to $10.5 \%$ in broiler diet had no detrimental effect on the performance of broiler chickens.

\section{REFERENCES}

Adebowale, E.A., Bamgbose, E., Ibigbemi, S. and Worgu, F. C. (1998) "Performance of Broilers Fed with Different Protein Sources". Proceedings of Silver Anniversary Conference of Nigeria Society for Animal Production (NSAP), West African Society for Animal Production, Inaugural Conference.Abeokuta, March 21 - 25. Pp529-597.

Adejumo, D.O., Onifade, A.A., Olutende, T.O. and Babatunde, G.M. (2005) "The Effect of Concentration, 'Age and Duration of Feeding Supplemental Yeast (Levucel SB) in a High Fiber Diet on the Performance of Broiler Chickens". Journal of Sustainable Tropical Agricultural Research.13:58-65.

Adeniji, A. A. (1996) "The Value of Bovine Blood Rumen Content meal As a Feedstuff for Pullets".Ph.D Thesis, University of Ilorin, Nigeria.

Adeniji, A.A. and Balogun , O. O. (2001) "Chemical Evaluation of Bovine Blood Rumen Content Meal". Journal of Agricultural Research and Development.pp. 75-79, Faculty of Agriculture, University of llorin.

AOAC.(1990) Association of Official Analytical Chemists. Official Methods of Analysis, Washington D.C.

Apata, D.F. (2008) "Growth Performance and Nutrient Digestibility and Immune Response of Broiler Chicks Fed Diets Supplemented with a Culture of Lactobacillus vulgaris".Journal of Science Food and Agriculture. 88: 1253-1258.

Balogun, O.O., Adeniji, A.A., Bamgbose, A and Ibigbemi, S. (2001) "Performance of layers fed graded levels of blood rumen content mixture".Journal of Agricultural Research and Development. Pp.1-7, Faculty of Agriculture, University of llorin

Bolu, S.A. and Ibikunle, M. (2009) "Alternative/Conventional Feedstuff in Broiler Production in Nigeria".Agrosearch. 10(1\&2):55-63. 
Bouzaine, T., Dulphin, R.D., Thonart, P., Urdarci, M.C. and Amdi, M. (2005) "Adherence and Colonization Properties of Lactobaccilus rhamnosis TB1, a Broiler Chicken Isolate". Journal of Applied Microbiology. 40: 391-396.

Charlie, W.S. (1998) "Yeast Products in Feed Industry".A practical guide for feed professionals. Diamond Mills. Inc. Cedar Rapids IOWA.

Chaucheyras, F., Fonty, G.,Bertin, G. and Gouret, P. (1995) "Effects of Live Saccharomycescerivisae Cells on Zoospore Germination, Growth and Cellulolytic Activity of The Rumen Anaerobic Fungus Neoccallimastris frontalis". Current Microbiology.31:21-205.

Chichlowski, M., Groom, J., McBride, B.W., Havenstein, G.B. and Koci, M.D. (2007) "Metabolic and Physiological Impacts of Probiotics or Direct Fed Microbes on Poultry.A Brief Review of Current Knowledge".International Journal of Poultry Science.6 (10) 694 -704.

Church, D.C. (1973) "Digestive Physiology and Nutrition of Ruminants".Published by D.C. Church Vol. 1. pg. 143-189.

Cummings, J.H. and Macfarlane (1997) "Role of Intestinal Bacteria in Nutrient Metabolism".Journal of Parenteral and Enteral Nutrition. 21:357-363.

Fayeye, T.R. and Olapade, A.A. (2013) "Hatch Out Analysis and Repeatability Estimates of Common Hatchability Problems in Isa Brown Breeder Stock". Agrosearch.13(2): 51 -58.

Duncan, D.B. (1955) Multiple Range and Multiple F-tests.Biometrics. 11:1-42.

Ignacio, C.O.D. (1995) "Evaluation of the Effects of Yeast on Growth Performance of Broiler Chickens". Poultry Science Association.74 (Suppl.1) 565.

Kizerwetter- Swida, M. and Binck, M. (2009) "Protective Effect of Potentially Probiotic Lactobacillus Strains on Infection with Pathogenic Bacteria in Chickens". Polish Journal of Veterinary Science. 12: $15-20$.

Mead, G.C. (1989) "Microbes of the Avian Caecum; Types Present and Substrates Utilized".Journal of Experimental Zoology. 3: 48-54.

Newbold, C.J., Wallace, R.J., Chen, X.B. and Mentoish, F.M. (1995) "Different Strains of Saccharomyces cerevisae Differ in Their Effects on Ruminal Bacteria Numbers in vitroand in Sheep".Journal of Animal Science. 73:1811-1818.

Oludoyi, I.A. and Toye, A.A. (2012) "The Effects of Early Feeding of Moringa oleifera Leaf Meal on Performance of Broiler and Pullets Chicks". Agrosearch. 12 (2): 160-172.

Oyedeji, J. O., Ajayi, H. I. and Egere T. (2008) "The Effects of Increasing Levels of Yeast Culture (Levucel SB) in High Fiber Diet on The Performance of Broiler Chickens". Journal of Sustainable Tropical Agricultural Research. 13:58-65.

Patterson, J.A. and Burkholder, K. (2003) "Application of Prebiotics and Probiotics in Poultry Production". Poultry Science. 82:627-631.

SAS, (2005) Statistical Analysis System, Institute Inc. User Guide. Carry, North Carolina USA.

Yoon, I.K. and Stern, M. D. (1996) "Effect of Saccharomyces cerevisae and Aspergillus oryzae Culture on Ruminal Fermentation in Dairy Cow". Journal of Dairy Science.79: 411 -417. 
Oyedeji,Ajayi, Epoudo, Edem \& Sokondi

Table 1: Percentage composition of the broiler starter diets used in the experiment (0 - 4 weeks)

\begin{tabular}{lcccr}
\hline & Treatments & & & \\
\cline { 2 - 5 } Ingredients & T1 & T2 & T3 & T4 \\
& $0.0 \%$ & $3.5 \%$ & $7.0 \%$ & $10.5 \%$ \\
\hline Maize & BRCM & BRCM & BRCM & BRCM \\
Soybean meal & 50.00 & 45.00 & 43.00 & 40.00 \\
Fish meal & 39.00 & 35.25 & 31.75 & 28.25 \\
Wheat offal & 1.75 & 2.38 & 3.25 & 4.03 \\
Blood- Rumen Content Mixture & 2.00 & 4.00 & 5.00 & 7.00 \\
Palm oil & 0.00 & 3.50 & 7.00 & 10.50 \\
Bone meal & 3.00 & 3.00 & 3.50 & 3.75 \\
Limestone & 2.25 & 2.62 & 2.75 & 2.97 \\
Yeast & 1.30 & 1.35 & 1.45 & 1.37 \\
Salt & 0.00 & 0.25 & 0.25 & 0.25 \\
Methionine & 0.25 & 0.25 & 0.25 & 0.25 \\
Lysine & 0.10 & 0.10 & 0.10 & 0.10 \\
*Vitamin Premix & 0.10 & 0.10 & 0.10 & 0.10 \\
Grit & 0.25 & 0.25 & 0.25 & 0.25 \\
\hline Total & 1.00 & 1.95 & 1.35 & 1.18 \\
\hline Nutrient Content (Analysed) & 100 & 100 & 100 & 100 \\
& & & & \\
Dry Matter (\%) & & & & \\
Crude Protein (\%) & & & & \\
Crude Fat (\%) & 90.33 & 90.81 & 90.82 & 90.71 \\
Crude Fibre (\%) & 24.45 & 23.34 & 22.23 & 21.30 \\
Total Ash (\%) & 7.09 & 7.74 & 5.51 & 4.67 \\
\hline
\end{tabular}

* Provided g kg of diet-vitamin $A(12,000 \mathrm{IU}) ;$ Vitamin $D_{3}(2,500 \mathrm{IU})$; Vitamin $E(30,000 \mathrm{IU})$ Vitamin $\mathrm{K}_{3}$ (2,000mg); Vitamin B2-Riboflavin (3mg); Vitamin B3- Nicotinic acid (10mg); Vitamin B5(15meg)Pantothenicacid (15,000 mg); Manganese (80,000 mg); Zinc (50mg); Copper $(5 \mathrm{mg})$; lodine(1,000mg); Cobalt (Co) (0.2mg); Selenium (Se) (0.1mg); Folic acid (1,500mg); Biotin (50meg); Choline chloride (300,000mg) 
Table 2: Percentage composition of the Broiler finisher diets used in the experiment (5 - 8 weeks)

\begin{tabular}{|c|c|c|c|c|}
\hline \multirow{4}{*}{ Ingredient } & \multicolumn{4}{|c|}{ Treatment } \\
\hline & T1 & T2 & T3 & T4 \\
\hline & $0.0 \%$ & $3.5 \%$ & $7.0 \%$ & $10.5 \%$ \\
\hline & BRCM & $\mathrm{BRCM}$ & BRCM & $\mathrm{BRCM}$ \\
\hline Maize & 50.00 & 45.00 & 46.00 & 50.00 \\
\hline Soya bean meal & 30.00 & 26.25 & 22.27 & 19.25 \\
\hline Fish meal & 2.30 & 3.00 & 3.00 & 2.30 \\
\hline Wheat offal & 7.00 & 9.00 & 10.00 & 13.28 \\
\hline Blood- Rumen Content Mixture & 0.00 & 3.50 & 7.00 & 10.50 \\
\hline Palm oil & 4.00 & 5.20 & 5.31 & 4.00 \\
\hline Bone meal & 2.85 & 3.10 & 2.98 & 2.69 \\
\hline Limestone & 1.65 & 1.62 & 1.85 & 1.93 \\
\hline Yeast & 0.00 & 0.25 & 0.25 & 0.25 \\
\hline Salt & 0.25 & 0.25 & 0.25 & 0.25 \\
\hline Methionine & 0.10 & 0.10 & 0.10 & 0.10 \\
\hline Lysine & 0.10 & 0.10 & 0.10 & 0.10 \\
\hline *Vitamin Premix & 0.25 & 0.25 & 0.25 & 0.25 \\
\hline Grit & 1.50 & 2.40 & 3.14 & 4.25 \\
\hline Total & 100 & 100 & 100 & 100 \\
\hline \multicolumn{5}{|l|}{ Nutrient Content (Analysed) } \\
\hline Dry Matter (\%) & 90.09 & 91.39 & 92.63 & 94.79 \\
\hline Crude Protein (\%) & 21.55 & 21.55 & 20.25 & 19.54 \\
\hline Crude Fat (\%) & 9.58 & 8.16 & 6.01 & 4.69 \\
\hline Crude Fibre (\%) & 6.78 & 8.53 & 9.27 & 13.95 \\
\hline Total Ash (\%) & 16.66 & 27.27 & 21.60 & 34.25 \\
\hline
\end{tabular}

* Provided $\mathrm{g} \mathrm{kg}^{-1}$ of diet-vitamin $A(12,000 \mathrm{IU}) ;$ Vitamin $\mathrm{D}_{3}(2,500 \mathrm{IU}) ;$ Vitamin $E(30,000 \mathrm{IU})$ Vitamin $\mathrm{K}_{3}$ (2,000mg); Vitamin B2-Riboflavin (3mg); Vitamin B3- Nicotinic acid (10mg); Vitamin B5(15meg)Pantothenicacid (15,000mg); Manganese (80,000mg); Zinc (50mg); Copper(5mg); lodine(1,000mg); Cobalt (Co) (0.2mg); Selenium (Se) (0.1mg); Folic acid (1,500mg); Biotin (50meg); Choline chloride $(300,000 \mathrm{mg})$ 
Table 3: Proximate composition of Blood Rumen Content Mixture (BRCM) on as fed basis.

\begin{tabular}{|ccccccc|}
\hline $\begin{array}{c}\text { Moisture } \\
(\%)\end{array}$ & $\begin{array}{c}\text { Dry Matter } \\
(\%)\end{array}$ & $\begin{array}{c}\text { CP } \\
(\%)\end{array}$ & $\begin{array}{c}\text { Crude Fat } \\
(\%)\end{array}$ & $\begin{array}{c}\text { CF } \\
(\%)\end{array}$ & $\begin{array}{c}\text { Ash } \\
(\%)\end{array}$ & $\begin{array}{c}\text { NFE } \\
(\%)\end{array}$ \\
\hline 9.53 & 90.47 & 23.78 & 9.17 & 20.40 & 10.87 & 26.53 \\
\hline
\end{tabular}

Table 4: Effects of Blood Rumen Content Mixture meal on the performance of broiler chickens

\begin{tabular}{llcccc}
\hline Level of BRCM (\%) & & & & & \\
Parameter & 0 & 3.5 & 7.0 & 10.5 & SEM \\
\hline Feed intake kg/bird & $2.42^{\mathrm{b}}$ & $2.80^{\mathrm{a}}$ & $2.71^{\mathrm{a}}$ & $2.80^{\mathrm{a}}$ & 0.18 \\
Weight gain $\mathrm{kg} / \mathrm{bird}$ & 1.20 & 1.34 & 1.46 & 1.37 & 0.33 \\
Feed gain ratio & 2.10 & 2.08 & 1.86 & 2.12 & 0.49 \\
Percentage mortality & $7.40^{\mathrm{a}}$ & $4.20^{\mathrm{b}}$ & $7.90^{\mathrm{a}}$ & $4.20^{\mathrm{b}}$ & 2.00 \\
\hline
\end{tabular}

${ }^{a, b}$ means carrying different superscripts within rows are significantly different $(p<0.05)$ BRCM: blood rumen content mixture

Table 5: Effects of Blood Rumen Content Mixture meal on the gut microbial population of broiler chickens at 4 weeks

\begin{tabular}{lllll}
\hline & \multicolumn{2}{c}{ Dilution $10^{-2}$} & \multicolumn{2}{c}{ Dilution10-3 } \\
Diet & lleum & Caecum & \|leum & Caecum \\
\hline $0.0 \%$ BRCM & $29^{\mathrm{b}}$ & $45^{\mathrm{b}}$ & $16^{\mathrm{b}}$ & $21^{\mathrm{b}}$ \\
$3.5 \%$ BRCM & $120^{\mathrm{a}}$ & $78^{\mathrm{a}}$ & $46^{\mathrm{b}}$ & $68^{\mathrm{a}}$ \\
$7.0 \%$ BRCM & $113^{\mathrm{a}}$ & $45^{\mathrm{b}}$ & $103^{\mathrm{a}}$ & $74^{\mathrm{a}}$ \\
$10.5 \%$ BRCM & $53^{\mathrm{b}}$ & $102^{\mathrm{a}}$ & $20^{\mathrm{b}}$ & $53^{\mathrm{ab}}$ \\
SEM & 44.76 & 27.77 & 40.10 & 23.71 \\
\hline
\end{tabular}

$a, b$ means carrying different superscripts within columns are significantly different $(p<0.05)$ BRCM: blood rumen contentmixture 
Oyedeji,Ajayi, Epoudo, Edem \& Sokondi

Table 6: Effects of Blood Rumen Content Mixture meal on gut microbial population of broiler chickens at 8 weeks.

\begin{tabular}{llcll}
\hline & \multicolumn{2}{c}{ Dilution 10-2 } & \multicolumn{2}{c}{ Dilution10-3 } \\
& lleum & Caecum & lleum & Caecum \\
\hline $0.0 \%$ BRCM & $54^{\mathrm{b}}$ & $52^{\mathrm{b}}$ & $81^{\mathrm{a}}$ & $13^{\mathrm{a}}$ \\
$3.5 \%$ BRCM & $40^{\mathrm{b}}$ & $54^{\mathrm{b}}$ & $40^{\mathrm{b}}$ & $41^{\mathrm{b}}$ \\
$7.0 \%$ BRCM & $46^{\mathrm{b}}$ & $40^{\mathrm{b}}$ & $56^{\mathrm{b}}$ & $31^{\mathrm{b}}$ \\
$10.5 \%$ BRCM & $75^{\mathrm{a}}$ & $119^{\mathrm{a}}$ & $56^{\mathrm{b}}$ & $53^{\mathrm{b}}$ \\
SEM & 15.28 & 35.71 & 17.06 & 31.1 \\
\hline
\end{tabular}

${ }^{a, b}$ means carrying different superscripts within columns are significantly different $(p<0.05)$ BRCM: blood rumen content mixture

Table 7: Effects of Blood Rumen Content Mixture Meal on the types of gut microbes of broiler chickens

\begin{tabular}{lllllllll} 
& \multicolumn{2}{l}{ 0\% BRCM } & \multicolumn{2}{l}{$3.5 \%$ BRCM } & \multicolumn{2}{l}{$7.0 \%$ BRCM } & \multicolumn{2}{l}{$10.5 \%$ BRCM } \\
\cline { 2 - 9 } Micro Organisms & lleum & Caecum & lleum & Caecum & leum & Caecum & lleum & Caecum \\
\hline Bacillus sp & $\mathrm{P}$ & $\mathrm{P}$ & $\mathrm{P}$ & $\mathrm{P}$ & $\mathrm{P}$ & $\mathrm{P}$ & $\mathrm{P}$ & $\mathrm{NP}$ \\
Staphylococcus sp & $\mathrm{NP}$ & $\mathrm{NP}$ & $\mathrm{P}$ & $\mathrm{P}$ & $\mathrm{P}$ & $\mathrm{NP}$ & $\mathrm{P}$ & $\mathrm{NP}$ \\
Streptococcus sp & $\mathrm{NP}$ & $\mathrm{NP}$ & $\mathrm{NP}$ & $\mathrm{NP}$ & $\mathrm{NP}$ & $\mathrm{NP}$ & $\mathrm{P}$ & $\mathrm{NP}$ \\
\hline
\end{tabular}

BRCM: Blood Rumen Content Mixture

P: Present

NP: Notpresent 